\title{
Robotic-assisted pulmonary segmentectomies
}

\author{
Pierluigi Novellis ${ }^{1}$, Edoardo Bottoni ${ }^{1}$, Marco Alloisio ${ }^{1,2}$, Frank O. Velez-Cubian ${ }^{3}$, Eric M. Toloza ${ }^{3,4,5}$, \\ Giulia Veronesi ${ }^{1}$
}

${ }^{1}$ Thoracic Surgery Division, Humanitas Clinical and Research Center, Milan, Italy; ${ }^{2}$ Biomedical Science Department, Humanitas University, Milan, Italy; ${ }^{3}$ Department of Surgery, ${ }^{4}$ Department of Oncologic Sciences, University of South Florida Health Morsani College of Medicine, Tampa, FL, USA; ${ }^{5}$ Department of Thoracic Oncology, Moffitt Cancer Center, Tampa, FL, USA

Contributions: (I) Conception and design: P Novellis, G Veronesi; (II) Provision of study materials: G Veronesi, M Alloisio, EM Toloza; (III) Collection and assembly of data: P Novellis; (IV) Manuscript writing: All authors; (V) Final approval of manuscript: All authors.

Correspondence to: Pierluigi Novellis, MD. Thoracic Surgery Division, Humanitas Clinical and Research Center, Via Manzoni 56, 20089, Rozzano, Milano, Italy. Email: pierluigi.novellis@cancercenter.humanitas.it.

\begin{abstract}
The increased detection of early non-small cell lung cancers (NSCLCs) has allowed many surgeons to consider treatment of small peripheral lesions with intentional limited resection, which has gained much interest even in patients with low surgical risk. The minimally invasive approach to lung surgery has many benefits that have been widely reported. Robotic-assisted thoracoscopic surgery, similar to video-assisted thoracoscopic surgery (VATS), for lung cancer offers several advantages, including improved visualization and more precise instrument manipulation. Minimally invasive segmentectomy combines two beneficial aspects: first, the decreased surgical insult to the patient; second, the concept of "lung-sparing surgery", especially for those patients with reduced lung function. We report here a review of the literature about robotic-assisted segmentectomies. We will then describe the technique for specific segmentectomies, with related tips, tricks, and pitfalls.
\end{abstract}

Keywords: Robotic thoracic surgery; lung anatomic segmentectomies; indocyanine green (ICG)

Received: 17 August 2017; Accepted: 02 July 2018; Published: 09 August 2018.

doi: 10.21037 /jovs.2018.07.04

View this article at: http://dx.doi.org/10.21037/jovs.2018.07.04

\section{Introduction}

The concept of lung cancer resection has changed over the years. In 1995, Ginsberg and colleagues presented the results of a randomized trial comparing the oncologic outcome of patients with clinical stage-1 non-small cell lung cancer (NSCLC) undergoing conventional lobectomy versus limited resection (segmentectomy or wedge resection) (1). In that study, the benefits associated with lobectomy over sublobar resection included better parenchymal margins, better lymphatic sampling and clearance and sampling decreased local recurrence, and improved overall survival (OS) and disease-free survival (DFS). For over 10 years, the results of that study established pulmonary lobectomy as the gold standard for the radical surgical treatment of lung cancer. The limitations of Ginsberg's study were basically related to the lack of modern pre-operative staging. In addition, patients with tumor sizes up to $3 \mathrm{~cm}$, which have increased risk of occult metastasis, were all included in the randomization, and patients were submitted to lymph node sampling only, which could have led to understaging compared to complete lymph node dissection.

Although surgical resection remains the mainstay of treatment for early-stage lung cancers in patients without prohibitive surgical risk, thoracic oncology has changed significantly over the last 20 years. Many advances in the diagnosis and management of lung cancer have been made. With the dramatic increase of early detection of ever smaller NSCLCs due to the development of improved radiographic tools and the widespread use of low-dose helical computerized tomography (CT) scans for lung cancer screening (2), many surgeons have inevitably become concerned over the treatment of small peripheral lesions with resection of an entire pulmonary lobe, such that intentional limited resection has gained much interest, even in patients with low surgical risk. 
In 2006, Okada and colleagues (3) analyzed a number of non-randomized studies and concluded that sublobar resection should be considered as an alternative to lobectomy for stage-IA NSCLCs that were $2 \mathrm{~cm}$ or less, even in patients with low surgical risk. Since 2006, more evidence has been accumulated and shows that sublobar resection for lung cancer lesions smaller than $2 \mathrm{~cm}$ are oncologically effective. This new concept of lung cancer treatment with less radical resection, combined with an improved understanding of lung cancer staging, has challenged the conclusions of the Ginsberg study of 1995 (1). Subsequently, the rate of pulmonary lobectomies has decreased from 1998 to 2012, whereas the rate of sublobar resections has increased and offset the decrease in lobectomies (4).

Anatomic segmentectomy is the resection of one or more bronchopulmonary segments, with the ligation and division of the corresponding bronchus and vessels serving those segments. Data comparing segmental resection with lobectomy are still limited. In 2008, the Cancer and Leukemia Group B (CALGB) proposed a randomized study (5) with the aim to evaluate the "non-inferiority" in OS of segmentectomy compared to lobectomy in patients with peripheral stage-IA NSCLC that are $\leq 2 \mathrm{~cm}$. In 2009, another phase-III study was started in Japan to evaluate the non-inferiority in OS of segmentectomy compared with lobectomy in patients with small (diameter less than $2 \mathrm{~cm}$ ) peripheral NSCLC, excluding radiologically determined non-invasive cancer. This study opened in August 2009 and planned to accrue a total of 1,100 patients from 71 institutions over 3 years (6). The results of these studies have not yet been published, but will provide objective data on segmental resections.

Until then, current guidelines on the treatment of stage-I and stage-II NSCLC, in patients who are medically fit for surgical resection, a lobectomy rather than sublobar resection is recommended (Grade 1B) in patients who are medically fit for surgical resection (7). For patients with clinical stage-I NSCLC and who may tolerate operative intervention but not a lobar resection due to decreased pulmonary function or comorbid disease, sublobar resection is recommended over nonsurgical therapy (Grade 1B) (7).

The minimally invasive approach to lung surgery has many benefits that have been widely reported, including being a less traumatic approach, reduced postoperative pain, reduced impairment in respiratory muscle, reduced cytokine production, improved immune surveillance, and improved survival (8-12). Some studies compared "open" segmentectomy to thoracoscopic segmentectomy and concluded that thoracoscopic segmentectomy is a safe and feasible procedure, with reduced hospital length of stay and with comparably favorable OS $(13,14)$. For experienced thoracoscopic surgeons, thoracoscopic segmentectomy appears to be a sound option for lung-sparing, anatomic pulmonary resections. Nevertheless, because it is a technically demanding operation, whose difficulties are compounded by the inherent disadvantages of video-assisted thoracoscopic surgery (VATS), i.e., rigid instruments restricting maneuverability, loss of the eye-hand-target axis, and only two dimensional visualization, most anatomic VATS surgery are performed by a small number of highly experienced thoracoscopic surgeons $(15,16)$, and very few series of VATS segmentectomy are available (17).

Robot-assisted surgery for lung cancer was introduced in $2002(18,19)$. After a slow start, use of a robot to perform lobectomy and other pulmonary resections has increased rapidly since 2009. Several studies indicate that roboticassisted surgery for lung resection is safe and is associated with similar oncologic outcomes to VATS and open surgery $(20,21)$. Furthermore, robot-assisted lung surgery offers several advantages to the surgeon, including improved visualization and more precise and comfortable instrument manipulation $(22,23)$.

A recent meta-analysis comparing robotic-assisted segmentectomies with conventional VATS segmentectomies (24) confirmed that the robotic approach is a feasible and safe method for radical resection of lung cancer. In 2012, Pardolesi and colleagues were the first to describe a case series of patients undergoing pulmonary segmentectomy $(25,26)$. Their study reported on 17 patients $(7$ men, 10 women), mean age 68.2 years (range, 32-82 years), who underwent robotic-assisted pulmonary segmentectomy from 2008 to 2010, and revealed that robotic-assisted anatomic segmentectomy is feasible and safe. This technique appears well-suited to the precise dissection required for anatomic segmentectomy, even though the indications in this initial experience were restricted to patients with single-lesion early-stage lung cancer or with metastasis from a non-lung site, all less than $2 \mathrm{~cm}$ in diameter. This entire series was characterized by absence both of major bleeding during surgery and of hemothorax during the postoperative period.

In 2014, Toker et al. (27) reported on 21 patients (15 with malignant disease), who underwent robotic-assisted pulmonary segmentectomy using the da Vinci system (Intuitive Surgical Corp.; Sunnyvale, California, USA). There were no conversions to thoracotomy. The authors 
concluded, with the previously cited study, that robotassisted thoracoscopic segmentectomy for malignant and benign lesions was practical, safe, and associated with few complications and short postoperative hospitalization. They also noted that the number of lymph nodes removed appeared "oncologically acceptable" for early-stage lung cancer patients and that, to evaluate postoperative pain, respiratory function, and quality of life (QOL), a prospective comparison with VATS segmentectomy was necessary.

In 2015, Demir and colleagues (28) upload their case series publishing a report on 99 patients who underwent robotic-assisted thoracoscopic (RATS; $n=34$ ) and VATS $(n=65)$ pulmonary segmentectomies at two institutions. Seventy-six patients underwent surgery for malignancy and 23 for benign diseases. The major morbidity rates were $24 \%$ for RATS versus $23 \%$ for VATS $(\mathrm{P}=0.57)$, and mortality rates were $0 \%$ for RATS versus $1.5 \%$ for VATS $(\mathrm{P}=0.66)$. The mean console time for RATS was longer than the mean operation time for VATS $[76 \pm 23$ (range, $40-150$ ) vs. $65 \pm 22$ (range, $30-120$ ) $\mathrm{min} ; \mathrm{P}=0.018$ ]. The mean duration of chest tube drainage was similar for RATS and VATS [3.5 \pm 2.3 (range, 1-10) vs. 4.0 3.6 (range, 1-21) days; $\mathrm{P}=0.90]$. The duration of postoperative hospital stay for RATS was $4.6 \pm 1.9$ days (range, $2-10$ days) and for VATS was $6.2 \pm 4.7$ days (range, $2-24$ days) $(\mathrm{P}=0.39)$. Demir and colleagues concluded that both RATS and VATS pulmonary segmentectomy operations were performed with similar morbidity and mortality rates. Although the duration of operation was longer in RATS when compared with an established VATS program, there was a tendency towards a shorter postoperative hospital stay.

Rinieri and colleagues in 2016 (29) reported on the perioperative outcomes of VATS and robot-assisted segmentectomies. The minimally invasive segmentectomies included 32 VATS and 16 robot-assisted procedures, with patient characteristics, type of segment, conversion to thoracotomy, conversion to lobectomy, operative time, postoperative complications, chest tube duration, postoperative hospital stay, and histology being similar in the VATS and robot-assisted groups. Estimated blood loss was significantly higher in the VATS group (100 vs. $50 \mathrm{~mL} ; \mathrm{P}=0.028$ ). They concluded that the morbidity rate of minimally invasive segmentectomy was low and that the short-term results of VATS and robot-assisted segmentectomies were similar, but that more data were required to show any advantages between the two techniques.
In 2016, Cerfolio reported on his series of roboticassisted segmentectomies (30). Between February 2010 and December 2014, 100 patients underwent surgery with a planned pulmonary segmentectomy. A robotic-assisted approach was chosen for all. Indications for resection were lung cancer in 79 patients, metastatic lesions in 10 patients, and other conditions in 11 patients. Seven patients underwent conversion to robotic-assisted lobectomy, and the remaining 93 patients had a robotic-assisted anatomic segmentectomy. There were no conversions to thoracotomy. The median blood loss was $20 \mathrm{~mL}$ (range, $10-120 \mathrm{~mL}$ ), the median number of lymph nodes removed was 19 , the median operative time was 1.28 hours (88 minutes), the median hospital length of stay was 3 days, and major morbidity occurred in 2 patients (pneumonia in both). All patients had undergone R0 resection. There were no 30- or 90-day mortalities. Of the 79 patients with lung cancer, the median follow-up was 30 months, and 3 patients (3.4\%) had recurrence in the operated lobe. OS was $95 \%$ at 30 months. Cerfolio and colleagues concluded that completely portal robotic-assisted anatomic segmentectomy is a safe and effective technique and offers outstanding intraoperative, 30-day, and 90-day results, with a recurrence rate of approximately $3 \%$ at 2.5 years.

Also in 2016, Echavarria and colleagues presented a comparison of pulmonary function tests (PFTs) and perioperative outcomes after robotic-assisted pulmonary lobectomy $v s$. segmentectomy (31). They analyzed data from 251 consecutive patients who underwent roboticassisted lobectomy $(n=208)$ or segmentectomy $(n=43)$ by a single surgeon over 36 months. PFTs and perioperative outcomes were compared using Chi-squared test, unpaired Student's $t$-test, or Kruskal-Wallis test, with significance at $\mathrm{P} \leq 0.05$. Intraoperative complications were not significantly different, but median operative times were longer for robotic-assisted segmentectomies $(\mathrm{P}=0.01)$. Postoperative complications were not significantly different, except for increased rates of pneumothorax after chest tube removal $(\mathrm{P}=0.032)$ and of effusions or empyema $(\mathrm{P}=0.011)$ after robotic-assisted segmentectomies. Predicted changes for forced expiratory volume in 1 second (FEV1) and diffusion constant of the lung for carbon monoxide (DLCO) were significantly less after robotic-assisted segmentectomy $(\mathrm{P}<0.001)$. Those authors concluded that robotic-assisted segmentectomy should be considered as an alternative to lobectomy for conserving lung function in respiratorycompromised lung cancer patients, although oncologic efficacy remains undetermined. 


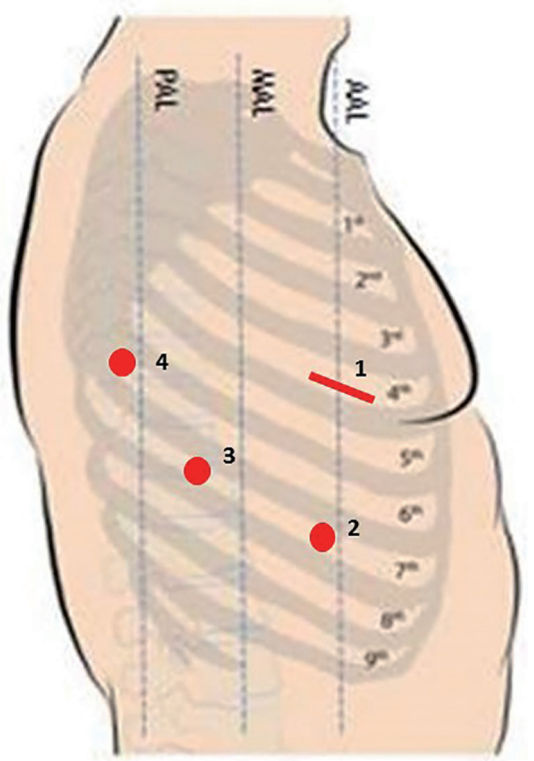

Figure 1 Anterior technique with four arms, 1 is the $2.5 \mathrm{~cm}$ utility incision; 2 is an $8 \mathrm{~mm}$ port used for camera; 3 and 4 are ports used for the robotic arms.

\section{Patient selection and pre-operative preparation}

Patients who are candidates to undergo robotic-assisted segmentectomy are those with a T1a-T1b $\left(8^{\text {th }}\right.$ edition TNM Staging) N0 lung cancer, patients with lung cancer $>2 \mathrm{~cm}$ but $<3 \mathrm{~cm}$ with limited FEV $1<60 \%$ of predicted, or patients with pulmonary metastases. All patients undergo CT scan of the chest with contrast and a fluorodeoxyglucose (FDG)-positron emission tomography (PET). A staging scan of the brain is usually not required for clinical stage-I patients, because the incidence of occult brain metastasis in stage-I lung cancer is low, and routine brain imaging results in increased costs, delays therapy, and rarely changes patient management (32). A wide variation in use of brain imaging for staging between centers suggests either lack of awareness or disagreement about this Choosing Wisely recommendation (33).

Standard preoperative tests include chest X-ray, electrocardiogram (ECG), blood tests, and PFTs. Additional testing for cardiopulmonary evaluation is used on a selective basis. Anesthesiologic management is similar to the one described previously for robotic-assisted resection of N2 lung cancer. Patients undergoing segmental resection are sometimes more affected by comorbidities, so patient selection should be optimized (34).

\section{Procedures for segmental lung resection}

The patient position that we usually use in robotic-assisted lung surgery has been previously described (35). Briefly, the patient is positioned in lateral decubitus, and the dependent portions of the body and arms are padded appropriately. The operating table is flexed at the level of the kidney rest. A 4-arm robotic approach is typically used with da Vinci Xi System (Figure 1), although a 3 -arm robotic approach can be used and has been described (Figure 2) (31).

For the 4-arm approach, a utility incision of 3-5 cm is performed in the 4th intercostal space anteriorly, and a skin retractor (Alexis ${ }^{\circledR}$ Wound Protector; Applied Medical; Rancho Santa Margarita, California, USA) is placed. Under thoracoscopic visualization with the thoracoscope at the $4^{\text {th }}$ intercostal utility incision, an 8-mm camera port is introduced through the 7 th or 8 th intercostal space at the anterior axillary line. Two other ports are introduced under thoracoscopic visualization in the same intercostal space, when possible, as the camera port-one in line with the tip of the scapula and the other in the auscultatory triangle (Figure 1).

For the 3-arm approach, a $4.5-\mathrm{cm}$ port incision is created along the $6^{\text {th }}$ intercostal space at the anterior axillary line. With an 8 -mm camera port and the 30-degree-up robotic thoracoscope inserted through this $6^{\text {th }}$ intercostal port incision, a $1.5-\mathrm{cm}$ port incision is made along the $3^{\text {rd }}$ intercostal space at the anterior axillary line for a $12-\mathrm{mm}$ robotic port. Another $1.5-\mathrm{cm}$ port incision is made along the $9^{\text {th }}$ intercostal space at the posterior axillary line for another 12-mm robotic port (Figure 2).

\section{Right upper lobe anterior segmentectomy}

This operation starts by dissecting the anterior aspect of the pulmonary hilum and exposing the right superior pulmonary vein and distally the branch to the right upper lobe anterior segment. This anterior segmental pulmonary vein is ligated and divided between surgical clips or with a linear endostapler. Behind the divided pulmonary vein branch, the bronchus to the right upper lobe anterior segment is isolated and divided with a linear endostapler. More cephalad, the anterior trunk of the pulmonary artery can be found. The pulmonary artery to the right upper lobe anterior segment is isolated, ligated, and divided between surgical clips or with the linear endostapler. The intersegmental plane between the right upper lobe anterior segmental parenchyma is then separate from the apical and posterior segments of the right upper lobe by serial 


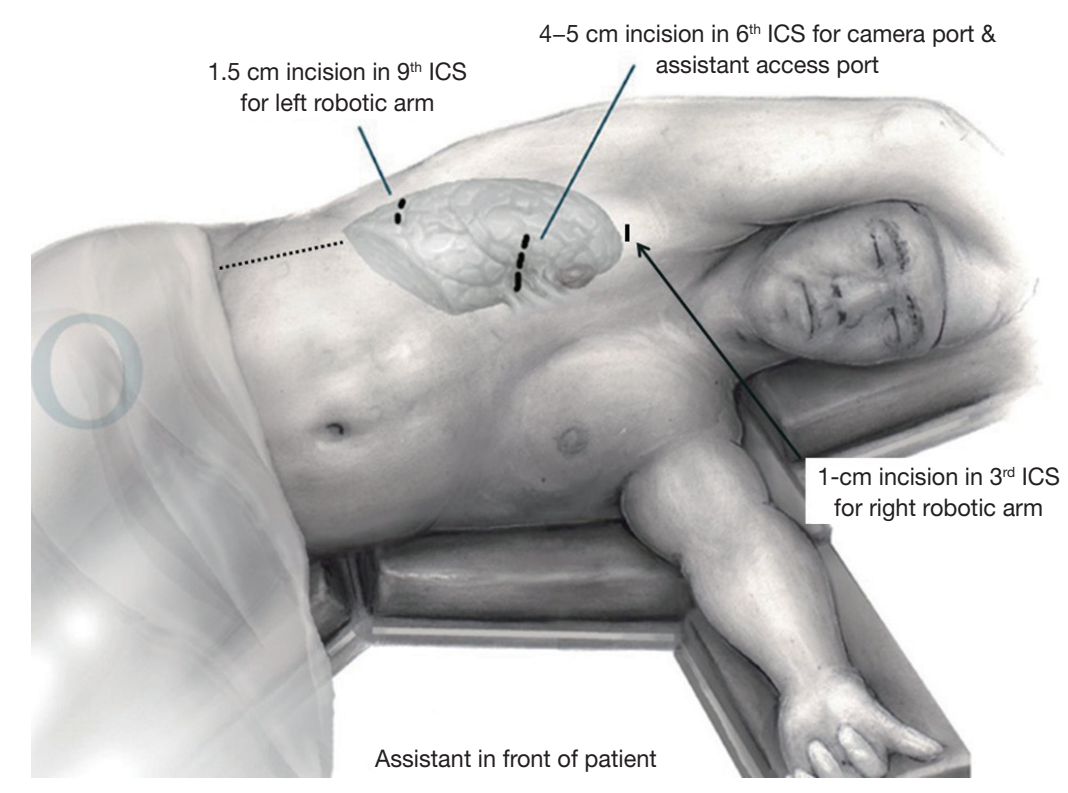

Figure 2 Anterior technique with three arms.

application of the linear endostapler and extracted from the chest within an endobag. Mediastinal lymph node stations are then dissected to complete the procedure.

\section{Right upper lobe apical segmentectomy}

This operation starts by dissecting the anterior aspect of the pulmonary hilum and exposing the right superior pulmonary vein and distally the branch to the right upper lobe apical segment. This apical segmental pulmonary vein is ligated and divided between surgical clips or with a linear endostapler. Superiorly, the anterior trunk of the pulmonary artery can be found. The pulmonary artery to the right upper lobe apical segment is the most cephalad branch and is ligated and divided. Posteriorly, the bronchus to the right upper lobe apical segment is dissected from the cephalad aspect of the right upper lobe bronchus and is ligated and divided. The apical segmental parenchyma is stapled from the anterior and posterior segments of the right upper lobe and extracted from the chest within an endobag. Then, mediastinal lymph node stations are dissected to complete the procedure.

\section{Right upper lobe posterior segmentectomy}

This operation begins by completing the oblique pulmonary fissure. Opening the intersection between the oblique and horizontal fissures, the pulmonary artery is exposed. Any hilar or interlobar lymph nodes encountered should be excised to help with the vascular dissection. The right upper lobe posterior ascending segmental branch of the pulmonary artery is dissected and ligated and divided between surgical clips or with a linear endostapler. The right upper lobe posterior segmental pulmonary vein will be found nearby. The posterior segmental vein is dissected off the right superior pulmonary vein and is ligated and divided. Then, the right upper lobe posterior segmental bronchus is transected between surgical clips or with a linear endostapler, and the right upper lobe posterior segment is removed from the field with an endobag. Mediastinal lymph node stations are then dissected to complete the procedure (Figure 3).

\section{Lingula-sparing left upper lobectomy (left upper lobe anteroapical bisegmentectomy)}

This operation begins with hilar and station 5 and 6 nodal dissection. The pulmonary vein for anterior and apicoposterior segments is dissected from the lingular branches of the left superior pulmonary vein, ligated, and divided between surgical clips or with a linear endostapler. The anterior trunk of the pulmonary artery appears immediately behind the divided anteroapical segmental pulmonary vein and is isolated, ligated, and divided between surgical clips or with the linear endostapler. Then, depending on the anatomy, the bronchus for the segment appears visible and is isolated, ligated, and divided with 


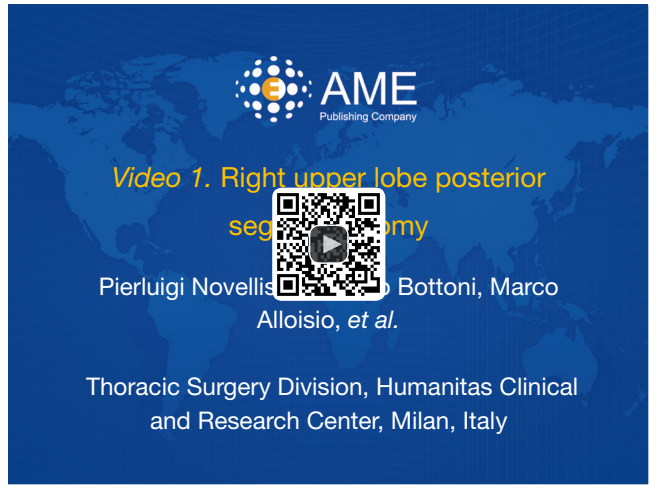

Figure 3 Right upper lobe posterior segmentectomy (36). Available online: http://www.asvide.com/article/view/26352

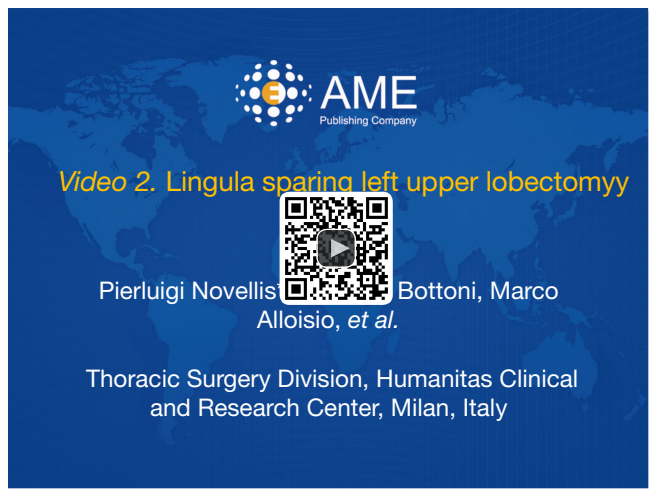

Figure 4 Lingula sparing left upper lobectomy (37).

Available online: http://www.asvide.com/article/view/26353

the linear endostapler. Often after the bronchus has been divided, a posterior segmental pulmonary artery branch is found and is isolated, ligated, and divided between surgical clips or with the linear endostapler. Using lung insufflation or intravenous indocyanine green (ICG) administered by the anesthesiologist, the anteroapical bisegment is divided from the lingular segments of the left upper lobe and extracted from the chest within an endobag. Note that all endostaplers are introduced during this segmental operation through the port in line with the tip of the scapula. This operation ends after dissection of nodal stations 7, 8, and 9, which is performed posterior to the anteriorly retracted remaining right lung (Figure 4).

\section{Lingulectomy}

This operation begins with hilar and station 5 and 6 nodal dissection. The lingular segmental pulmonary vein is isolated from the anteroapical segmental branches of the left superior pulmonary vein, ligated, and divided between surgical clips or with a linear endostapler. Then, the pulmonary fissure is developed, and the lingular segmental pulmonary artery branch appears on anterior aspect of the left main pulmonary artery. The lingular pulmonary artery branch is isolated and is ligated and divided between surgical clips or with the linear endostapler. Then, the anterior portion of the pulmonary fissure, between the lingula and left lower lobe, is divided with the linear endostapler. Lingular bronchus can then be identified and is isolated and divided with the linear endostapler. Using left lung insufflations or intravenous ICG administered by the anesthesiologist, the lingular segments are divided from the anteroapical segments of the left upper lobe by serial application of the linear endostapler and extracted from the chest within an endobag. Note that all endostaplers during this operation can be introduced through the utility incision, although sometimes the endostapler for the lingular segmental pulmonary vein is introduced through the port in line with the tip of the scapula. This operation ends after the dissection of nodal stations 7,8 , and 9 , which is performed posterior to the anteriorly retracted remaining left lung.

\section{Superior segmentectomy of the right or left lower lobe}

This operation begins with the division of the inferior pulmonary ligament and dissection of nodal stations 9,8 , and 7. The pulmonary fissure is divided, and the lower lobe superior segmental artery branch appears posteriorly from the pulmonary artery and is isolated, ligated, and divided between surgical clips or with a linear endostapler. After retracting the lung anteriorly and exposing the posterior aspect of the pulmonary hilum, the lower lobe superior segmental pulmonary vein is isolated from the inferior pulmonary vein, ligated, and divided between surgical clips or with the linear endostapler. The posterior part of the oblique pulmonary fissure, if not complete, is divided with the linear endostapler, and the lower lobe superior segmental bronchus becomes visible, sometimes after mobilization of the basilar segmental pulmonary artery trunk. The lower lobe superior segmental bronchus is then isolated, ligated, and divided with the linear endostapler. The lower lobe superior segment is divided from the basilar segments of the lower lobe by serial application of the linear endostapler and extracted from the chest within an endobag. Note that all endostaplers can be introduced from the utility incision, but sometimes the endostapler used for 


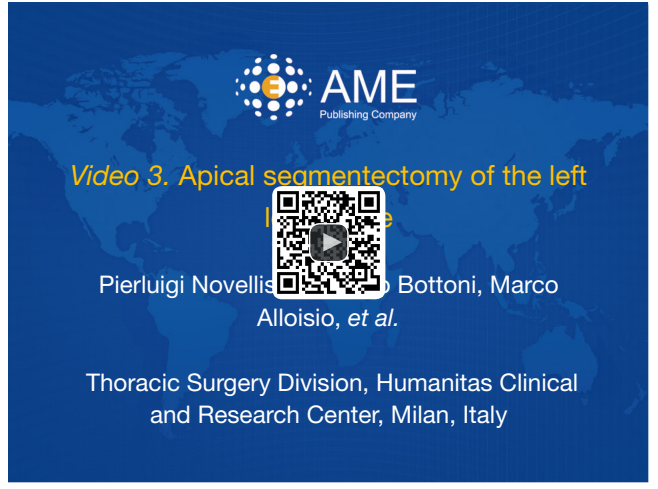

Figure 5 Apical segmentectomy of the left lower lobe (38). Available online: http://www.asvide.com/article/view/26354

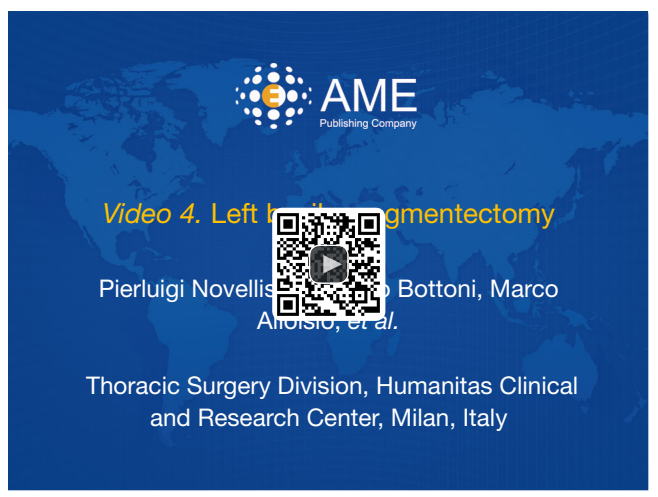

Figure 6 Left basilar segmentectomy (39).

Available online: http://www.asvide.com/article/view/26355

the superior segmental pulmonary vein is introduced from the posterior port. The operation ends after the dissection of nodal stations 2 and 4 on the right and nodal stations 5 and 6 on the left (Figure 5).

\section{Basilar segmentectomy of the right or left lower lobe}

This operation begins by taking down the pulmonary ligament, and mediastinal station 9 lymph nodes are resected. The basilar and superior segmental branches of the inferior pulmonary vein are exposed, and attention is given to identifying, ligating, and dividing only the basilar segmental venous branches. Then, after opening the oblique pulmonary fissure, the pulmonary arterial branches to the superior and basilar segments are identified. The basilar segmental pulmonary artery branches are ligated and divided between surgical clips or with a linear endostapler. Interlobar station 11 lymph nodes are dissected off the bronchus. The basilar segmental bronchus is dissected proximally, and the superior segmental bronchus of the lower lobe is identified and spared. The basilar segmental bronchus is transected distal to the superior segmental bronchus. The basilar segments are stapled off the superior segment, and the specimen is extracted from the chest within an endobag. Then, mediastinal lymph node stations are dissected to complete the procedure (Figure 6).

\section{Use of ICG}

The most complex point in robotic-assisted segmentectomy is the identification of the intersegmental planes during the operation. Transbronchial injection of ICG during VATS surgery has been shown to facilitate quick and easy identification of the intersegmental planes defining the target lung segment without the need for lung inflation $(40,41)$. We described a simpler technique for the identification of intersegmental planes during roboticassisted anatomic segmentectomy (42). After division of the target segment bronchus, vein, and artery, within the hilum, peripheral intravenous injection of ICG "lights up" the non-target segments, while the target segment shows up as uncolored. ICG was prepared as a sterile solution (2.5 mg/10 mL) shortly before use. A 6- to $8-\mathrm{mL}$ bolus was injected into the peripheral vein catheter used to induce anesthesia, immediately followed by a $10-\mathrm{ml}$ saline solution bolus. During a minimally invasive approach that does not allow lung palpation, a clear view of the parenchyma demarcation of the intersegmental plane can render the anatomic sublobar procedure safer in terms of distance between the margins and tumor, in particular in the case of small nodules. The same results were obtained subsequently by Hsieh and colleagues (43).

\section{Tips, tricks, and pitfalls}

* Segmentectomy is normally performed if the pulmonary neoplasm, in the case of primary lung cancer, is less than two $\mathrm{cm}$ in greatest diameter. It is necessary to have an accurate three-dimensional location of the lung nodule in order to correctly identify the segment(s) to be removed. Sometimes preoperative localization of the lung nodule, such as by CT-guidance or by navigational bronchoscopy, can be performed in order to reduce the risk of leaving the lung nodule in the non-resected portion of the pulmonary lobe.

* Sometimes segmentectomy is performed in patients 
with reduced respiratory reserve and affected by emphysema. In this case, the ventilation at the end of the resection can cause air-trapping that may make very difficult the completion of the segmentectomy due to the resulting difficulties in re-deflating the lung.

* The absence of tactile feedback in robotic surgical technology makes it risky using the robotic instruments to isolate segmental vessels that are very small and more delicate then lobar vessels. Particular attention must be paid to the traction used during the segmentectomy.

* The identification of the intersegmental plan must be extremely accurate in order to maintain an adequate margin of at least $2 \mathrm{~cm}$.

\section{Conclusions}

The robotic approach to anatomic segmentectomy appears to offer all the advantages of minimally invasive surgery while providing the additional advantages of threedimensional visualization, greater dexterity, and greater surgeon comfort to thereby facilitate precise anatomic dissection, including lymphadenectomy, which promises to be oncologically radical.

The increasing number of screening for lung cancer is changing the scenario to which we were previously accustomed and which should lead to a reduction of advanced lung cancer stages at diagnosis and an increase of lung cancer diagnosed at earlier stages (2). We are also seeing an increase in the number of multiple lung tumors where a radical resection, even if lung sparing, is required $(44,45)$. The increase in the number of pulmonary tumors under $2 \mathrm{~cm}$ is obviously causing a change in the type of resection to be used. The results of the Ginsberg study (1) are now overcome. The present therapeutic goal is to perform "segmental radical" resections with removal of the lymphatic drainage pathways, which reduces the role of "wedge resection" as a therapeutic option (46).

The available results in the literature are based on retrospective analyses. However, these results show that, for tumors with a diameter of less than $2 \mathrm{~cm}$, segmentectomies have an OS similar to that achieved by traditional lobectomy (25,27-30). Nevertheless, the results of randomized trials are awaited and will be expected to provide more objective results $(5,6)$.

The concept of minimally invasive segmentectomy combines two beneficial aspects: first, the decreased surgical insult to the patient; second, the concept of "lungsparing surgery", especially for those patients with reduced lung function. While VATS segmentectomies have been described in the literature, the VATS approach is limited due to the rigidity of instruments and the 2-dimensional visualization that make this type of procedure much more complicated and surgically challenging, with long learning curves. Robotic-assisted lung surgery offers several advantages to the surgeon summarized as improved visualization and more precise and comfortable instrument manipulation $(23,47)$.

Principal limitations to the wide adoption of roboticassisted thoracic surgery are perceived as high capital and running costs of the robotic system and its instruments $(48,49)$. Furthermore, it would seem that use of robotic surgery, in general, has not improved patient outcomes as dramatically as did the first wave of minimally invasive surgery $(50,51)$. Thus, it is important to provide a balanced assessment of the advantages and disadvantages of roboticassisted surgery for lung surgery. As robotic surgical systems are an evolving technology, costs may fall as the technology matures, competitor manufacturers enter the field, and more machines become available (52).

\section{Acknowledgments}

We thank the Umberto Veronesi Foundation for fellowships to P Novellis.

Funding: None.

\section{Footnote}

Provenance and Peer Review: This article was commissioned by the Guest Editor (Hiroyuki Oizumi) for the series "VATS Segmentectomy" published in fournal of Visualized Surgery. The article has undergone external peer review.

Conflicts of Interest: The series "VATS Segmentectomy" was commissioned by the editorial office without any funding or sponsorship. GV serves as an unpaid editorial board member of Journal of Visualized Surgery from Jun 2018 to May 2020 and is a consultant for ABI Medica SpA and Medtronic. EMT is a consultant for Medtronic and an observation site for Intuitive Surgical Corp. The authors have no other conflicts of interest to declare.

Ethical Statement: The authors are accountable for all aspects of the work in ensuring that questions related to the accuracy or integrity of any part of the work are appropriately investigated and resolved. 
Open Access Statement: This is an Open Access article distributed in accordance with the Creative Commons Attribution-NonCommercial-NoDerivs 4.0 International License (CC BY-NC-ND 4.0), which permits the noncommercial replication and distribution of the article with the strict proviso that no changes or edits are made and the original work is properly cited (including links to both the formal publication through the relevant DOI and the license). See: https://creativecommons.org/licenses/by-nc-nd/4.0/.

\section{References}

1. Ginsberg RJ, Rubinstein LV. Randomized trial of lobectomy versus limited resection for T1 N0 non-small cell lung cancer. Lung Cancer Study Group. Ann Thorac Surg 1995;60:615-22; discussion 622-3.

2. National Lung Screening Trial Research Team, Aberle DR, Adams AM, et al. Reduced lung-cancer mortality with low-dose computed tomographic screening. N Engl J Med 2011;365:395-409.

3. Okada M, Koike T, Higashiyama M, et al. Radical sublobar resection for small-sized non-small cell lung cancer: a multicenter study. J Thorac Cardiovasc Surg 2006;132:769-75.

4. McMurry TL, Shah PM, Samson P, et al. Treatment of stage I non-small cell lung cancer: What's trending? J Thorac Cardiovasc Surg 2017. [Epub ahead of print].

5. Available online: https://jcto.weill.cornell.edu/open_ clinical_trials/calgb-140503-a-phase-3-randomized-trialof-lobectomy-versus-sublobar-resection-for-small

6. Nakamura K, Saji H, Nakajima R, et al. A phase III randomized trial of lobectomy versus limited resection for small-sized peripheral non-small cell lung cancer (JCOG0802/WJOG4607L). Jpn J Clin Oncol 2010;40:271-4.

7. Howington JA, Blum MG, Chang AC, et al. Treatment of stage I and II non-small cell lung cancer: Diagnosis and management of lung cancer, 3rd ed: American College of Chest Physicians evidence-based clinical practice guidelines. Chest 2013;143:e278S-e313S.

8. Walker WS. Video-assisted thoracic surgery (VATS) lobectomy: the Edinburgh experience. Semin Thorac Cardiovasc Surg 1998;10:291-9.

9. Giudicelli R, Thomas P, Lonjon T, et al. Video-assisted minithoracotomy versus muscle-sparing thoracotomy for performing lobectomy. Ann Thorac Surg 1994;58:712-7; discussion 717-8.

10. Nagahiro I, Andou A, Aoe M, et al. Pulmonary function, postoperative pain, and serum cytokine level after lobectomy: a comparison of VATS and conventional procedure. Ann Thorac Surg 2001;72:362-5.

11. Craig SR, Leaver HA, Yap PL, et al. Acute phase responses following minimal access and conventional thoracic surgery. Eur J Cardiothorac Surg 2001;20:455-63.

12. Leaver HA, Craig SR, Yap PL, et al. Lymphocyte responses following open and minimally invasive thoracic surgery. Eur J Clin Invest 2000;30:230-8.

13. Atkins BZ, Harpole DH Jr, Mangum JH, et al. Pulmonary segmentectomy by thoracotomy or thoracoscopy: reduced hospital length of stay with a minimally-invasive approach. Ann Thorac Surg 2007;84:1107-12; discussion 1112-3.

14. Linden D, Linden K, Oparka J. In patients with resectable non-small-cell lung cancer, is video-assisted thoracoscopic segmentectomy a suitable alternative to thoracotomy and segmentectomy in terms of morbidity and equivalence of resection? Interact Cardiovasc Thorac Surg 2014;19:107-10.

15. Petersen RP, Pham D, Burfeind WR, et al. Thoracoscopic lobectomy facilitates the delivery of chemotherapy after resection for lung cancer. Ann Thorac Surg 2007;83:1245-9.

16. Hartwig MG, D'Amico TA. Thoracoscopic lobectomy: the gold standard for early-stage lung cancer? Ann Thorac Surg 2010;89:S2098-101.

17. Atkins BZ, Harpole DH, Magnum JH, et al. Pulmonary segmentectomy by thoracoscopy: reduced hospital length of stay with a minimally invasive approach. Ann Thorac Surg 2007;84:1107-12.

18. Melfi FM, Menconi GF, Mariani AM, et al. Early experience with robotic technology for thoracoscopic surgery. Eur J Cardiothorac Surg 2002;21:864-8.

19. Giulianotti PC, Coratti A, Angelini M, et al. Robotics in general surgery: personal experience in a large community hospital. Arch Surg 2003;138:777-84.

20. Gharagozloo F, Margolis M, Tempesta B, et al. Robotassisted lobectomy for early-stage lung cancer: report of 100 consecutive cases. Ann Thorac Surg 2009;88:380-4.

21. Veronesi G, Galetta D, Maisonneuve P, et al. Four-arm robotic lobectomy for the treatment of early-stage lung cancer. J Thorac Cardiovasc Surg 2010;140:19-25.

22. Park BJ, Melfi F, Mussi A, et al. Robotic lobectomy for non-small cell lung cancer (NSCLC): long-term oncologic results. J Thorac Cardiovasc Surg 2012;143:383-9.

23. Nasir BS, Bryant AS, Minnich DJ, et al. Performing robotic lobectomy and segmentectomy: cost, profitability, and outcomes. Ann Thorac Surg 2014;98:203-8. 
24. Liang H, Liang W, Zhao L, et al. Robotic Versus Videoassisted Lobectomy/Segmentectomy for Lung Cancer: A Meta-analysis. Ann Surg 2018;268:254-9.

25. Pardolesi A, Park B, Petrella F, et al. Robotic anatomic segmentectomy of the lung: technical aspects and initial results. Ann Thorac Surg 2012;94:929-34.

26. Pardolesi A, Veronesi G. Robot-assisted lung anatomic segmentectomy: technical aspects. Thorac Surg Clin 2014;24:163-8, vi.

27. Toker A, Ayalp K, Uyumaz E, et al. Robotic lung segmentectomy for malignant and benign lesions. J Thorac Dis 2014;6:937-42.

28. Demir A, Ayalp K, Ozkan B, et al. Robotic and videoassisted thoracic surgery lung segmentectomy for malignant and benign lesions. Interact Cardiovasc Thorac Surg 2015;20:304-9.

29. Rinieri P, Peillon C, Salaün M, et al. Perioperative outcomes of video- and robot-assisted segmentectomies. Asian Cardiovasc Thorac Ann 2016;24:145-51.

30. Cerfolio RJ, Watson C, Minnich DJ, et al. One Hundred Planned Robotic Segmentectomies: Early Results, Technical Details, and Preferred Port Placement. Ann Thorac Surg 2016;101:1089-95.

31. Echavarria MF, Cheng AM, Velez-Cubian FO, et al. Comparison of pulmonary function tests and perioperative outcomes after robotic-assisted pulmonary lobectomy vs segmentectomy. Am J Surg 2016;212:1175-82.

32. Choosing Wisely. The Society of Thoracic Surgeons. Available online: http://www.choosingwisely.org/societies/ the-society-of-thoracic-surgeons/, accessed September 9, 2015.

33. Balekian AA, Fisher JM, Gould MK. Brain Imaging for Staging of Patients With Clinical Stage IA Non-small Cell Lung Cancer in the National Lung Screening Trial: Adherence With Recommendations From the Choosing Wisely Campaign. Chest 2016;149:943-50.

34. Veronesi G, Novellis P, Difrancesco O, et al. Robotic assisted lobectomy for locally advanced lung cancer. J Vis Surg 2017;3:78.

35. Veronesi G, Novellis P, Voulaz E, et al. Robot-assisted surgery for lung cancer: State of the art and perspectives. Lung Cancer 2016;101:28-34.

36. Novellis P, Bottoni E, Alloisio M, et al. Right upper lobe posterior segmentectomy. Asvide 2018;5:672. Available online: http://www.asvide.com/article/view/26352

37. Novellis P, Bottoni E, Alloisio M, et al. Lingula sparing left upper lobectomy. Asvide 2018;5:673. Available online: http://www.asvide.com/article/view/26353

38. Novellis P, Bottoni E, Alloisio M, et al. Apical segmentectomy of the left lower lobe. Asvide 2018;5:674. Available online: http://www.asvide.com/article/ view $/ 26354$

39. Novellis P, Bottoni E, Alloisio M, et al. Left basilar segmentectomy. Asvide 2018;5:675. Available online: http://www.asvide.com/article/view/26355

40. Sekine $\mathrm{Y}$, Ko E, Oishi H, et al. A simple and effective technique for identification of intersegmental planes by infrared thoracoscopy after transbronchial injection of indocyanine green. J Thorac Cardiovasc Surg 2012;143:1330-5.

41. Oh S, Suzuki K, Miyasaka Y, et al. New technique for lung segmentectomy using indocyanine green injection. Ann Thorac Surg 2013;95:2188-90.

42. Pardolesi A, Veronesi G, Solli P, et al. Use of indocyanine green to facilitate intersegmental plane identification during robotic anatomic segmentectomy. J Thorac Cardiovasc Surg 2014;148:737-8.

43. Hsieh CP, Liu YH, Wu YC, et al. Indocyanine green fluorescence-navigated robotic segmentectomy. Surg Endosc 2017;31:3347-8.

44. Jiang L, He J, Shi X, et al. Prognosis of synchronous and metachronous multiple primary lung cancers: Systematic review and meta-analysis. Lung Cancer 2015;87:303-10.

45. Bonanno L, Calabrese F, Nardo G, et al. Morphological and genetic heterogeneity in multifocal lung adenocarcinoma: The case of a never-smoker woman. Lung Cancer 2016;96:52-5.

46. Nakamura H, Taniguchi Y, Miwa K, et al. Comparison of the surgical outcomes of thoracoscopic lobectomy, segmentectomy, and wedge resection for clinical stage I non-small cell lung cancer. Thorac Cardiovasc Surg 2011;59:137-41.

47. Veronesi G. Robotic lobectomy and segmentectomy for lung cancer: results and operating technique. J Thorac Dis 2015;7:S122-30.

48. Melfi FM, Mussi A. Robotically assisted lobectomy: learning curve and complications. Thorac Surg Clin 2008;18:289-95, vi-vii.

49. Demmy TL, Curtis JJ. Minimally invasive lobectomy directed toward frail and high-risk patients: a case-control study. Ann Thorac Surg 1999;68:194-200.

50. Hoksch B, Ablassmaier B, Walter M, et al. Complication rate after thoracoscopic and conventional lobectomy. Zentralbl Chir 2003;128:106-10. 
51. Nakata M, Saeki H, Yokoyama N, et al. Pulmonary function after lobectomy: video-assisted thoracic surgery versus thoracotomy. Ann Thorac Surg 2000;70:938-41.

doi: 10.21037/jovs.2018.07.04

Cite this article as: Novellis P, Bottoni E, Alloisio M, Velez-Cubian FO, Toloza EM, Veronesi G. Robotic-assisted pulmonary segmentectomies. J Vis Surg 2018;4:166.
52. Novellis P, Alloisio M, Vanni E, et al. Robotic lung cancer surgery: review of experience and costs. J Vis Surg 2017;3:39. 